\title{
El Tratado de Libre Comercio con México
}

\author{
Eduordo Ayolo Grimoldi \\ Viceministro de Economío
}

$\mathrm{M}$ uy buenas tardes a todos ustedes. En primer lugar debo agradecer este honor de poder estar aquí en ASI y agradecer a su presidente $y$ a todas las autoridades de la Universidad Tecnológica, porque esta es la segunda vez que me dan el honor de participar en una actividad organizada por ellos.

Voy a tratar de resumir un poco lo que es el Tratado de Libre Comercio con México. Es un tratado que demoró en firmarse y ha sido una de las preguntas que clásicamente nos hacen en los foros donde hablamos, demoró seis años, cosa que algunos consideran que es mucho tiempo, pero nosotros creemos que fue el tiempo justo para lograracuerdos beneficiosos para ambos. Un proceso de negociación que para nosotros fue marcado por el interés de llegar a acuerdos que fueran asimétricos, acuerdos que considerarán las diferencias de tamaño de las economías y acuerdos, que ba jo el mandato de los señores presidentes, tomarán en cuenta estas diferencias de desarrollo. Nos dimos a la tarea de concretar en la realidad lo que sería la asimetría. Podemos con satisfacción expresar alıora de que este tratado recogió todos los objetivos que nosotros nos propusimos desde el inicio, de asimetria en particular y como un aspecto principal.

\section{Acuerdos asimétricos}

Encontramos buena acogida después de muchas discusiones de parte del equipo negociador mexicano $y$ en particular de parte del Secretario Derminio Blanco, concretamente en lo que concierne a la asimetría que tiene relación con varias áreas del tratado. En primer lugar en áreas de acceso al mercado, en donde contamos con un programa de grabación diferenciado, básicamente y utilizando términos muy sencillos podemos decir que México va a abrir los mercados mucho más rápido para los productos salvadoreños de lo que El Salvador lo hará y en general el triángulo norte, como una forma de permitir un ajuste necesario en nuestras indust rias para poder estar en condiciones de incorporarse a una nueva realidad con México en un clima de libre comercio.
Asimetrías también en lo que se refiere a una relación comercial bajo un TLC como son las reglas de origen. Reglas de origen que nosetros concebimos eomo la base del acceso al mercado, en el sentido de que una regla de origen que no se puede cumplir por el tamaño de la industria o por los procesos productivos que se dan en la industria nacional es una regla de origen incumplible y por lo tanto hacen que los productos qued'en fuera del tratado y que sigan pagando aranceles.

En el tema de Reglas de origen está el conjunto completo de reglas para todos los productos, que consideran la realidad productiva de nuestros paises. Realidades de origen que hizo en algunos casos concebirse y adoptarlas de manera flexibles, para que pudieran ser cumplidas por parte de la industria nacional del triángulo norte. Reglas de origen mixtas, es decir aquellas que consideran un cambio arancelario como se conoce, pero que dan la opción cuando este cambio pudiera ser un poco rígido, dan la opción de una regla alternativa que flexibiliza el cumplimiento de estas reglas y en términos generales les puedo expresar que estas reglas de origen en su totalidad son cumplibles por parte de la industria nacional. Y siendo cumplibles por parte de la industria nacional harán que todos los productos salvadoreños que no quedaron fuera del tratado, puedan tener la oportunidad de ingresar al mercado mexicano en condiciones de libre comercio.

Por otra parte, también un objetivo común de los cuatro pais es asegurar el establecimiento de mecanismos que dieran seguridades a los productores nacionales, mecanismos que en términos generales puedo resumir en los siguientes: Primero garantizar la aplicación permanente de lo que es la salvaguardia global de la OMC. que es un mecanismo que ya tenemos, pero que reiteramos que los paises mantenemos el derecho de seguir aplicándola en el caso de invasión de productos al mercado de uno de los cuatro.

Tenemos también un mecanismo de salvaguardia bilateral que es adicional a esta salvaguardia general de la OMC, que permitirá poder enfrentar las importaciones masivas de productos, si asi se diera el caso, para 
lograr un alivio icmporal a la industrial o a la rama de producción nacional que se vea enfrentada a algún daño ociasionado por este incremente sustancial de las importaciones.

\section{Las salvaguardias}

También logramos establecer el mecanismo cle salvaguardia agricola especial, que es un mecanismo que se aplica a un listado de producios. En el caso de EI Salvador es una salvaguardia especial que el país puede aplicar y va aplicar a México. En el caso de Guatemala y' Honduras es una salvaguardia bilateral, en la cual tanto México como Guatemala y Honduras podrán aplicarlo. Y esta salvaguardia lo que hace básicamente es establecer cuolas anuales bajo un mecanismo especial que hacen que el programa cle desgravación que hemos estableciclo para ese producto en especial, se aplique única $y^{\prime}$ exclusivamente a una cuota anual y que el resto, el exceso cle esa cuola cle produclo que venga de México, pagará el arancel normal que paga todo producto cle cualquier país del mundo que ingresa al mercado salvacloreno. Lo cual hace que la apertura de estos productos sea cle una manera muy restringicia, progresiva y muy administrable, para evitar, dada la sensibilidad de estos productos agricolas, evitar cualquier perjuicio a la producción nacional.

Finalmente, lambién tenemos un mecanismo de protección aplicable a todo el tratado y a cualquier medida, que es el mecanismo de solución cle dilerencias, que le da seguridad a lodos los paises de que en caso uno de nosotros adopte medidas que violen el tratado o que perjudiquen los beneficios que esperamos recibiralgunos paises en este tratado, que podamos iniciar un proceso tencliente a la eliminación de esas medidas con la garantia de la
Murde\% y agilidad en el procese ye de la certidumbre yue nos dil el yue los compromisos yue hemos asumido en este tratado vian al ser cumplidos.

El caso cle los productos larmacéuticos, fue muy cliscuticlo en las mesas de negociación dado que teniamos un mecanismo que causaba problema para que nues tros productos pudieran llegar al mercado mexicano. Luego de muchas discusiones el gobierno mexicano asumió un compromiso muy imporiante para la relación comercial, cle modificar su legislación nacional en un plazo no mayor a dos anos. para permitir que los produciores cle medicamentos nacionales de El Salvador: Guatemala y Honduras, pudiesen incluir en el registro sanilário cle la Secrelaria de Salud de México. en forma directa sus productos y de esta manera el tratado les garantuza el acceso al mercado mexicano en condiciones de libre comercio

En lérminos generales queremos nosotros concluir, que este es un tratado que si no se llamara Trataclo cie Libre Comercio, creo que el mejor nombre sería un trataclo de milltiples oportuniclacles, para todos los sectores productivos de los cuatro paises. oportunidades cle incrementar las exportaciones a corto plazo. no śblo incrementarlas como lo hizo Costa Rica, sino superar a Costa Rica y convertirnos en los principales socios de México en la región. Poder cle esta manera incrementar nuestras exportaciones, tener un impacio muy positivo en la generación de empleo direcio en primer lugar de las empresas e industrias que van a producir más. para poder vender más al mercado mexicano. empleo indirecto por esta aclividad exportadora que se genera en los productores de los insumos que requiere la industria nacional. para poder producir y poder exporiar ese producto a México.

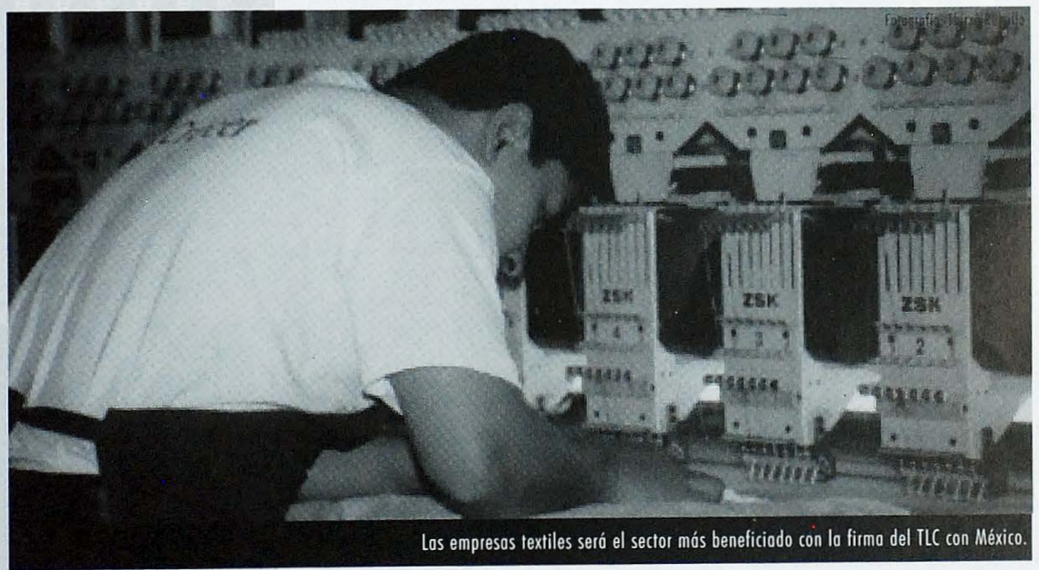


el tratado de libre comercio con México

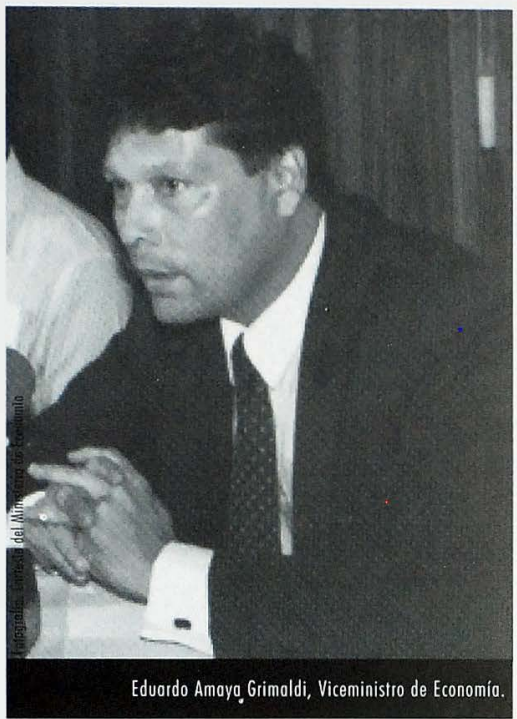

\section{Un tratado de oportunidades}

A mi me gusta poner un ejemplo cuando hablamos de empleo, si una empresa que produce boquitas, papas fritas. y tiene la oportunidad en el mercado mexicano de incrementar sus exporlaciones, va a requerir de incrementar también su producción. Mantener la calidad y poder tener precios $y^{\prime}$ calidad competitivos, no sólo en el mercado mexicano, sino también en el salvadoreño, ese incremento en la producción cle los snack cle papitas va a requerir una demanda importante de papas y la papa es un producto agricola, sector que se ve incentivado a producir más también. Para poder proveer de materia prima a la industria que hace las hoquitas y la produccion agricola de papas al incrementarse genera más empleo. pero también genera otro tipo de movimiemo en otras actividades comerciales $y^{\prime}$ de producción en el pais como pudiera ser el de los productores de fertilizantes. a mayor cantidad de área cultivada. a mayor calidad exigida en el producto, se requiere mayor consumo de insumos agricolas como podria ser los ferrilizantes, $y$ asi podemos enumerar una serie de aspectos que hacen que la generación de empleo no sólo impacte al sector productivo, que directamente produce para exportar. sino también a una cadena importante que hay internamente de producción que enlaza a la industria con otro tipo de productores que también resultan beneficiados por el tratado.
Este tratado es un tratado de oportunidades, oportunidades que dehemos aprovechar, oportunidades que en nuestras manos está el poder utizarlas de la mejor manera posible y clc esta forma lograr un beneficio no sólo para un sector productivo en especial, sino para todo el pais.

Finalmente les quiero contar últimas noticias, este día $y^{\prime}$ tal como lo habiamos previsto desde hace algunas semanas y básicamente en una reunión que sostuvimos con el Dr: Eduardo Solis, lucgo de la conclusión de las negociaciones el pasado 10 de mayo. luvimos una reunión el dia siguiente donde básicaneme concehimos una forma de estructurar un programa de cooperación para apoyar una adecuada utilización del tratido y para poder promover en general todos los benelicios que podemos aprovechar del mismo.

El dia de ayer y ahora al medio dia se concluyó la negociación entre Mévico. Guatemala. Honduras ! El Salvador de un memorindum de entendimiento que nuestros ministros van a firmar el dia de la firma del tratado en forma paralcla. Un memoríndum de entendimiento de cooperación técnical en muchas áreas. en el área de promoción del comercio. en el área de promover el conocimiento de cuailes son las reglas del juego para el comercio en Mlévico. promover a través de bancomex la oferta exportable en nuestros paises a traves de una revista muy buena que bancomex edita y circula por todo el mundo. promover nuestra oferta exportable. promover lo que pudiera darse como inversión directa de México a nuestro pais y promover unal serie de medidas que incluso van tener al gún impacto en algunas lineas de crédito que a travis det Banco Mlultisectorial de Inversiones pudiéramos manc jar al corto plazo.

Esle es una muestra del espiritu de cooperación que eviste entre México y nosotros y el gran interés que todos tenemos de cue esie tratado sea utilizado al máximo al partir del primer dia.

Debo finalmente reconocer una labor muy importante en este proceso de negociación. que no sólo fue del equipo de negociaciones comerciales y de la Dirección de Política Comercial. sino un esfuerzo muy fuerte. un esfuerzo muy prof undo de parte de Rigoberto Monge. como coordinador de las negociaciones del sector privado nacional y de todos los sectores productivos a quicnes Rigoberto tocó la puerta en innumerables ocasiones y dada esal labor de detalle que tuvimos que hacer! cle una negociación casi de producto por producto y de reglas de origen en forma cspecitica. labor cue Rigoberto! su equipo realizó. podemos ahora sentirnos muy satisfechos de cue ese soporte y esal unión de un trabajo conjunto entre el sector privaido y el gobierno facilitóllegarar a concluir un buen tratado de libre comercio con Mévico. 